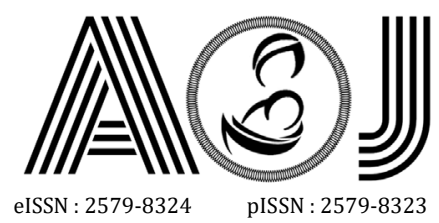

\title{
RESEARCH
}

\section{The Relationship between Menopause and Depression in Padang}

Arde Hidayat $^{1}$, Ariadi $^{2}$, Firdawati ${ }^{2}$

Affiliation author: 1. H. Hanafie District Hospital, Muaro Bungo, Jambi, Indonesia; 2. Obstetrics and Gynecology Department, Faculty of Medicine, Andalas University, Dr. M. Djamil Central General Hospital Padang, West Sumatera, Indonesia; 3. Public Health Department, Faculty of Medicine, Andalas University Padang, West Sumatera, Indonesia

Correspondence to: Arde Hidayat, email: rieck.arde@gmail.com, Hp: 085274135085

\section{Abstract}

Objectives: to analyze the relationship between menopause and depression in Padang

Methods : This type of research is an analytical observational with a comparative cross sectional approach that looks at the relationship between menopause and depression incidence. The research was conducted in the working area of the Padang City Health Center from April to June 2020. The instrument used in this study was the Hamilton Depression Rating Scale (HDRS / Ham-D) which was used to measure the level of depression and a questionnaire to ask questions related to the characteristics of the respondents.

Results: A study was conducted on 170 people consisting of 85 respondents who had menopause and 85 respondents who had not yet menopause.

Conclusion: As many as 50 (58.8\%) menopausal respondents experienced depression and 35 (41.2\%) respondents did not experience depression. There is a relationship between menopause and depression $(p<0.05)$. There was a relationship between age, current medical history, income, occupation, and education level with the incidence of depression $(p<0.05)$. There is no relationship between menopause duration, marital status, and BMI with depression incidence ( $p>0.05$ )

Keywords: depression, Hamilton Depression Rating Scale, menoupause

\section{INTRODUCTION}

Menopause is a condition in which a woman is no longer menstruating permanently due to the loss of activity of ovarian follicles. ${ }^{1-4}$ Natural menopause is said to be amenorrhoea for 12 consecutive months without any pathological or physiological abnormalities. Ovarian activity began to decrease in the late $30 \mathrm{~s} .{ }^{2,4,5}$ Menopause occurred at a mean age of 51 years, the number of remaining follicles fell below the critical threshold of about 1000 regardless of the age of the woman. Menopause consists of several stages, namely pre-menopause, menopause, and postmenopause. ${ }^{1}$

The World Health Organization (WHO) estimates that the number of postmenopausal women in the world will increase from around 476 million in 1990 to 1.2 billion in 2020. This is influenced, among others, by population growth and increasing life expectancy slowly and progressively. An increase in life expectancy has also occurred in Indonesia as a result of the 


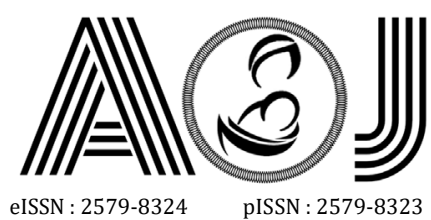

eISSN : 2579-8324
pISSN : 2579-8323

success of the national health program so that the elderly population, known as the elderly, has also increased. Since 2004 - 2015 shows an increase in Life Expectancy in Indonesia from 68.6 years to 70.8 years and the projection for 2030-2035 is 72.2 years. In 2015, West Sumatra was ranked 7th in the elderly population level. Meanwhile, in Padang, the number of elderly people in 2019 is around 68,509 people. Based on gender, the population of elderly women is more than men, the increase in the population of elderly women is directly proportional to the population of menopausal women. The increase in life expectancy resulted in an increase in the burden on the Indonesian economy, namely around $48.63 \% .6,7,8$

Epidemiological research shows that about 1 in 5 women will experience an episode of major depressive disorder (MDD) at some point in life. ${ }^{7}$ MDD incidence in women is twice that of men. ${ }^{8}$ In the world $5-18 \%$ of women are post menopausal experiencing depressive symptoms. According to WHO data (2016), there are about 35 million people affected by depression. In Indonesia, with a variety of biological, psychological and social factors with a diverse population, the number of cases of mental disorders continues to increase which has an impact on increasing the burden on the country and decreasing human productivity in the long term. ${ }^{7}$ Riskesdas 2018 data shows the prevalence of mental emotional disorders as indicated by symptoms depression and anxiety for those aged 15 years and over account for about $6.1 \%$ of Indonesia's population. ${ }^{6}$ For some women, depression can appear or worsen during periods of dynamic hormonal changes such as premenstrual, peripartum, and perimenopause. Longitudinal studies conducted on women and the pre to post-menopausal stages of the reproductive cycle, indicate that some women show a higher sensitivity to changes in gonadal thyroid and thus are at risk of developing negative mood symptoms so that patients with a history of severe premenstrual mood symptoms are associated with an increased risk for onset or perimenopausal MDD relapse. ${ }^{7}$

An increased risk of depressive symptoms in the transition to menopause has been repeatedly observed in population-based studies. In the Penn Ovarian Aging Study (POAS), the risk of depressive symptoms was nearly three times greater in the menopausal transition compared with premenopausal women, while women with no prior history of depression reported 2.5 times depressed mood in the menopausal transition compared with when they were premenopausal. ${ }^{7,8}$ With an increase in life expectancy it will be followed by an increase in the number of menopausal women so that the risk of depression events also increases. Complaints that occur during menopause can affect the quality of life of women, one of which is related to the incidence of MDD. Decreasing quality of life is accompanied by increased morbidity and the need for treatment, this will increase the government's economic burden. Handling of health problems for elderly women should be done multidisciplinary. Therefore, research on menopause and its relationship with the incidence 


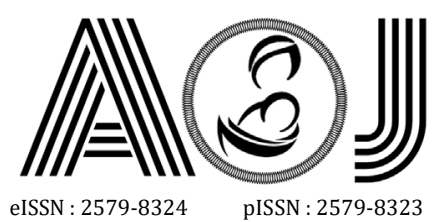

eISSN : 2579-8324
pISSN : 2579-8323

of depression is important to do so that it can plan prevention measures for depression and management of depression in menopausal patients more comprehensively involving multidisciplinary measures.

\section{PURPOSE}

This study aims to determine relationship between menopause and depression incidence in Padang.

\section{METHOD}

This type of research is an analytical observational with a comparative cross sectional approach that looks at the relationship between menopause and depression incidence. The research was conducted in the working area of the Padang City Health Center from April to June 2020. The population of this study were all menopausal and pre-menopausal women with an age range of 45 - 60 years ( 8 years after FMP) who were in the working area of Puskesmas Kota Padang. Samples to be taken are menopausal and pre-menopausal women who come to health centers that meet the inclusion criteria.

Menopausal population inclusion criteria

1) Willing to be research respondents

2) Has no history of depression

3) Women have menopause up to $\leq 8$ years since the beginning of menopause

4) Not in therapy / hormone replacement use

Inclusion criteria for the pre-menopausal population

1) Willing to be research respondents

2) Has no history of depression

3) Women aged 45-55 years and do not meet menopausal criteria

4) Not currently using hormonal contraception

Sampling was done by multistage random sampling. The first stage was cluster random sampling, where out of eleven sub-districts in Padang City, six districts were selected. The second stage was cluster random sampling of twelve health centers from six previously selected sub-districts and obtained eight health centers.

The instrument used in this study was the Hamilton Depression Rating Scale (HDRS / Ham-D) which was used to measure the level of depression and a questionnaire to ask questions related to the characteristics of the respondents. 


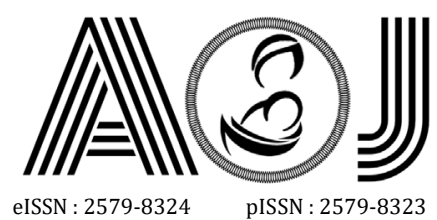

eISSN : 2579-8324
pISSN : 2579-8323

Editorial Room Andalas Obstetrics and Gynecology Journal, $3^{\text {rd }}$ floor of KSM of Obstetrics and Gynecology,

RSUP DR. M. Djamil Padang, Jl. Perintis Kemerdekaan Padang, Sumatera Barat 25127

Before this research began, an ethical clearance was submitted to the Research Ethics Commission Team of the Faculty of Medicine, Andalas University, and had received an ethical clearance statement number 314 / KEP / FK / 2020.

\section{RESULT}

A study was conducted on 170 people consisting of 85 respondents who had menopause and 85 respondents who had not yet menopause. Research respondents were taken from eight working areas of public health centers in Padang City, namely Air Dingin Health Center, Seberang Padang Health Center, Nanggalo Health Center, Padang Pasir Health Center, Pauh Health Center, Lubuk Buaya Health Center, Anak Air Health Center, and Bungus Health Center.

\section{Respondent Characteristics}

Table 1. Characteristics of Research Respondents

\begin{tabular}{|c|c|c|}
\hline \multirow{2}{*}{ Characteristics } & Depression & Not Depressed \\
\hline & Mean \pm SD & Mean \pm SD \\
\hline Age (year) & $53.5 \pm 5.3$ & $50.5 \pm 4.9$ \\
\hline \multirow[t]{2}{*}{ Duration of menopause (year) } & $4.7 \pm 2.3$ & $4.3 \pm 2.6$ \\
\hline & $f(\%)$ & $f(\%)$ \\
\hline \multicolumn{3}{|l|}{ Marital status } \\
\hline a. Widow & $14(58.3)$ & $10(41.7)$ \\
\hline b. Married & $56(38.4)$ & $90(61.6)$ \\
\hline \multicolumn{3}{|l|}{ BMI } \\
\hline a. Overweight & $30(43.5)$ & $39(56.5)$ \\
\hline b. Normal & $40(39.6)$ & $61(60.4)$ \\
\hline \multicolumn{3}{|l|}{ Current medical history } \\
\hline a. Present & $35(63.6)$ & $20(36.4)$ \\
\hline b. Not present & $35(30.4)$ & $80(69.6)$ \\
\hline \multicolumn{3}{|l|}{ Income } \\
\hline a. Not enough & $20(95.2)$ & $1(4.8)$ \\
\hline b. Enough & $50(33.6)$ & $99(66.4)$ \\
\hline \multicolumn{3}{|l|}{ Occupation } \\
\hline a. Not working & $43(50.6)$ & $42(49.4)$ \\
\hline b. Working & $27(31.8)$ & $58(68.2)$ \\
\hline \multicolumn{3}{|l|}{ Education } \\
\hline a. Low & $19(65.5)$ & $10(34.5)$ \\
\hline b. Moderate & $40(44)$ & $51(56)$ \\
\hline c. High & $11(22)$ & $39(78)$ \\
\hline
\end{tabular}

Based on Table 1, it is known that as many as 50 (58.8\%) menopausal respondents experienced depression and $35(41.2 \%)$ respondents did not experience depression. 


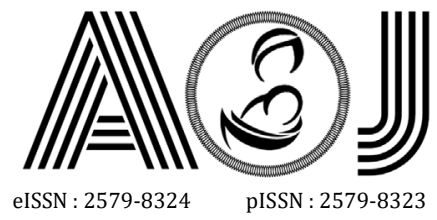

Editorial Room Andalas Obstetrics and Gynecology Journal, $3^{\text {rd }}$ floor of KSM of Obstetrics and Gynecology,

RSUP DR. M. Djamil Padang, Jl. Perintis Kemerdekaan Padang, Sumatera Barat 25127

Website:

http://jurnalobgin.fk.unand.ac.id/index.php/JOE

\section{Depression Frequency Distribution in Menopausal Women}

Table 2. Depression Frequency Distribution in Menopausal Women

\begin{tabular}{ccc}
\hline Depression Level & $f$ & $\%$ \\
\hline Depression & 50 & 58.8 \\
Not Depressed & 35 & 41.2 \\
Total & 85 & 100 \\
\hline
\end{tabular}

Based on Table 2, it is known that as many as 50 (58.8\%) menopausal respondents experienced depression and $35(41.2 \%)$ respondents did not experience depression.

\section{Distribution of Depression Frequency in Pre-menopausal Women}

Table 3. Distribution of Depression Frequency in Pre-menopausal Women

\begin{tabular}{ccc}
\hline Depression Level & $f$ & $\%$ \\
\hline Depression & 20 & 23.5 \\
Not Depressed & 65 & 76.5 \\
Total & 85 & 100 \\
\hline
\end{tabular}

Based on Table 3, it is known that more than half of the respondents who had menopause, namely 50 (58.8\%) of respondents experienced depression and more than half of the respondents who had not experienced menopause, namely $65(76.5 \%)$ of respondents were not experiencing depression. The results of statistical tests showed that there was a relationship between menopause and the incidence of depression $(p<0.05)$.

\section{The Relationship between Menopause and Depression}

Table 4. The Relationship between Menopause and Depression

\begin{tabular}{cccccccc}
\hline \multirow{2}{*}{ Menopause Status } & \multicolumn{3}{c}{ Depression Level } & \multicolumn{2}{c}{ Total } & \multirow{2}{*}{$\mathrm{p}$ value } \\
& \multicolumn{2}{c}{ Depression } & \multicolumn{2}{c}{ Not Depressed } & \multicolumn{2}{c}{ Tot } \\
\cline { 2 - 7 } & $\mathrm{f}$ & $\%$ & $\mathrm{f}$ & $\%$ & $\mathrm{f}$ & $\%$ & \\
\hline Menopause & 50 & 58.8 & 35 & 41.2 & 85 & 100 & \multirow{2}{*}{0.0001} \\
Not menopause & 20 & 23.5 & 65 & 76.5 & 85 & 100 & \\
Total & 70 & 41.2 & 100 & 58.8 & 124 & 100 & \\
\hline
\end{tabular}

Based on Table 4, The results of statistical tests showed that there was a relationship between menopause status and depression level $(p<0.05)$. 


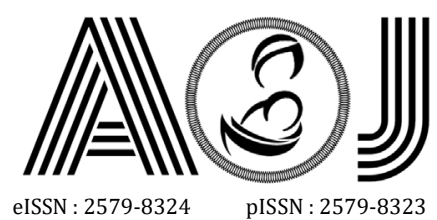

eISSN : 2579-8324
pISSN : 2579-8323

\section{DISCUSSION}

\section{Respondent Characteristics}

The results of this study indicate that the average respondents who experienced depression were older and the menopause was longer than respondents who did not experience depression.

Based on the marital status, depression is more experienced by women who are widowed. Depression is more experienced by women who have a history of current disease. In terms of income, depression is experienced by many respondents with insufficient income. Meanwhile, in terms of work and education, depression was experienced by many respondents who did not work and had low levels of education.

The results of research conducted by Zang et al (2016) stated that most postmenopausal women were in the age range of 56-60 years. Most of the length of education for postmenopausal women was less than six years, as much as $74.7 \%$. As many as $95.7 \%$ of postmenopausal women with marital status are married. More than half of postmenopausal women do not have chronic disease. Postmenopausal women who experienced depression in this study were $17.3 \% .^{9}$

\section{Incidence of Depression in Menopausal Women}

From this study it is known that more than half of menopausal women experience depression. A study conducted by Nobahar et al (2019) on 120 postmenopausal women, $22.5 \%$ experienced mild depression, $13.3 \%$ experienced moderate depression, and $1.7 \%$ experienced severe depression. Meanwhile, $46.7 \%$ of cases of anxiety had mild level of anxiety, $50.8 \%$ had moderate level of anxiety, and $2.5 \%$ had severe level of anxiety. In addition, $79.2 \%$ experienced mild stress and $20.8 \%$ experienced severe stress. Several observational studies have found that the transition to menopause is a period of increased risk of depression in women. ${ }^{10,11,12}$

The results of research conducted by Zang et al (2016) note that there is a difference in age ranges between menopausal women who are depressed and who are not depressed. Length of education, chronic illness, and marital status are not associated with the incidence of depression in menopausal women. Monthly income and sleep disturbances are associated with cases of depression. ${ }^{9}$

\section{Menopause Relationship with Depression Levels}

The results of this study indicate that there is a relationship between menopause and depression levels. The results of research conducted by Zang et al (2016) state that menopausal status which is divided into three groups, namely premenopause, perimenopause, and postmenopause is related to the incidence of depression. Some studies 


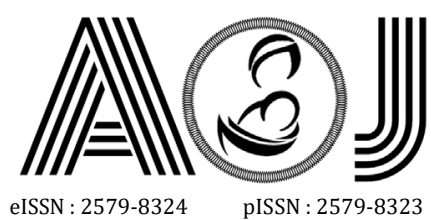

eISSN : 2579-8324
pISSN : 2579-8323

suggest that menopausal status is associated with an increased risk of depression due to hormonal changes. Research related to the relationship between depression and menopause has produced different findings where there is a stating that there is a relationship between menopause and depression or vice versa. This can be because the measuring instruments used in the study are also different. . $^{9,13,14,15}$

The clinical picture due to decreased estrogen levels is very complex, influenced by organobiological, psychological and socio-cultural aspects. From the organobiological point of view, symptom manifestations occur in organs that require these hormones. Psychologically, complaints can be found in the form of mood changes, depression and anxiety, sleep problems, fatigue, decreased sexual arousal, behavioral changes, and decreased cognitive function. Meanwhile, from the socio-cultural aspect, it can be seen that the role of the environment that can cause stress, namely the arrival of retirement, reduced role as parents, loss of spouse, decreased physical and social activity due to the impact of degenerative diseases..$^{9,16,17}$

\section{Factors Associated with the Incidence of Depression in Menopausal Women}

From the results of this study, it is known that the factors that influence the occurrence of depression in menopausal women are age, age of the oldest child, current medical history, income, employment, and education. Research conducted by Freeman et al (2012) found that age did not influence the incidence of depression, as did BMI, marital status, and occupation. In this study, it was explained that the onset of depressive symptoms and the onset of a diagnosis of depression significantly occurred when a woman was in the transition to menopause compared to premenopause. ${ }^{11,18}$

Several studies have stated that being unmarried (divorced, living alone), having a high or low level of education, and financial difficulties are major risk factors for depression during the menopausal transition. The results of a study conducted by Ma et al (2017) in Shanghai found that risk factors that can increase or decrease the risk of perimenopause depression are age, monthly income, health insurance, relationship with family, menstruation, perimenopause symptoms, severity of perimenopause symptoms, and physical activity. ${ }^{12,19,20}$

\section{CONCLUSION}

As many as 50 (58.8\%) menopausal respondents experienced depression and 35 (41.2\%) respondents did not experience depression. There is a relationship between menopause and depression ( $p 0.05)$. There was a relationship between age, current medical history, income, occupation, and education level with the incidence of depression $(p<0.05)$. There is no relationship between menopause duration, marital status, and BMI with depression incidence $(p>0.05)$. 


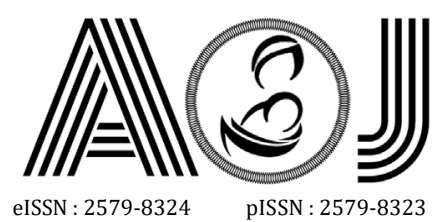

eISSN : 2579-8324
pISSN : 2579-8323

Editorial Room Andalas Obstetrics and Gynecology Journal, $3^{\text {rd }}$ floor of KSM of Obstetrics and Gynecology,

RSUP DR. M. Djamil Padang, Jl. Perintis Kemerdekaan Padang, Sumatera Barat 25127

Website:

http://jurnalobgin.fk.unand.ac.id/index.php/JOE

\section{REFERENCES}

1. The American College of Obstetricians and Gynecologists. Management of Menopausal Symptoms. Obstet Gynecol. 2014;123:202-216. doi:10.1097/aog.0000000000001229

2. Margaret R. Menopause for the MRCOG and Beyond. 2nd editio. Oxford: Cambridge University $\quad$ Press; 2008.2 doi:https://scihub.tw/https://doi.org/10.1017/СВ09781139696937

3. O'Neill S, Eden J. The pathophysiology of menopausal symptoms. Obstet Gynaecol Reprod Med. 2014;24(12):349-356. doi:10.1016/j.ogrm.2014.10.006

4. Berek JS. Berek \& Novak's Gynecology. 15th ed. Philadeplphia: Lippincott Williams \& Wilkins (LWW); 2019.

5. Goodman NF, Cobin RH, Ginzburg SB, Katz IA WD. American Association of Clinical Endocrinologists Medical Guidelines for Clinical Practice for The Diagnosis and Treatment of Menopause. AACE. 2011;17:1-25. papers3://publication/uuid/A1BBCBF9-7A48-4996-9DBF-007B0C704EDF.

6. Pusat Data dan Informasi Kementerian Kesehatan RI. Situasi Lanjut Usia (Lansia) di Indonesia. Jakarta: Kemenkes; 2016.

7. Bromberger J, Epperson N. Depression During and After the Perimenopause: Impact of Hormones, Genetics, and Environmental Determinants of Disease. Physiol Behav. 2018;45:663-678. doi:10.1016/j.ogc.2018.07.007

8. Georgakis MK, Thomopoulos TP, Diamantaras AA, et al. Association of Age at Menopause and Duration of Reproductive Period with Depression After Menopause: A Systematic Review and Meta-Analysis. JAMA Psychiatry. 2016;73(2):139-149. doi:10.1001/jamapsychiatry.2015.2653

9. Zang H, He L, Chen Y, Ge J, Yao Y. The association of depression status with menopause symptoms among rural midlife women in China. African Health Sciences. 2016;16(1):97-104.

10. Nobahar M, Naieni ZH, Ghorbani R. The prevalence of depression, anxiety, and stress and their association with vitamin $D$ and estrogen levels in postmenopausal women in Semnan. Middle East J Rehabil Health Stud 2019;6(4):1-7.

11. Freeman EW, Sammel MD, Lin H, Nelson DB. Associations of hormones and menopausal status with depressed mood in women with no history of depression. Arch Gen Psychiatry. 2006;63:375-82.

12. Ma M, Li RX, Xiao XR, Xu Y, Chen XY, Li B. A health survey of perimenopausal syndrome and mood disorders in perimenopause: a cross-sectional study in Shanghai. Int J Clin Exp Med. 2017;10(8):12382-403. 


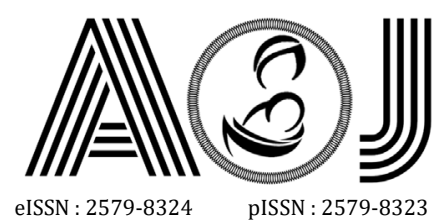

13. Zhao FY, Fu QQ, Kennedy GA, Conduit R, Zhang WJ, Zheng Z. Acupuncture as an Independent or Adjuvant Management to Standard Care for Perimenopausal Depression: A Systematic Review and Meta-Analysis. Front Psychiatry. 2021 May 28;12:666988. doi: 10.3389/fpsyt.2021.666988. PMID: 34122180; PMCID: PMC8192720.

14. Lei R, Sun Y, Liao J, Yuan Y, Sun L, Liu Y, Yang X, Ma W, Yu Z. Sex hormone levels in females of different ages suffering from depression. BMC Womens Health. 2021 May 22;21(1):215. doi: 10.1186/s12905-021-01350-0. PMID: 34022874; PMCID: PMC8141202.

15. Gujski M, Raczkiewicz D, Humeniuk E, Sarecka-Hujar B, Wdowiak A, Bojar I. Depressive Symptoms and Healthy Behavior Frequency in Polish Postmenopausal Women from Urban and Rural Areas. Int J Environ Res Public Health. 2021 Mar 14;18(6):2967. doi: 10.3390/ijerph18062967. PMID: 33799359; PMCID: PMC8001997.

16. An X, Yao X, Li B, Yang W, Cui R, Zhao G, Jin Y. Role of BDNF-mTORC1 Signaling Pathway in Female Depression. Neural Plast. 2021 Feb 9;2021:6619515. doi: 10.1155/2021/6619515. PMID: 33628219; PMCID: PMC7886502.

17. De Rosa N, Della Corte L, Giannattasio A, Giampaolino P, Di Carlo C, Bifulco G. Cancerrelated cognitive impairment $(\mathrm{CRCl})$, depression and quality of life in gynecological cancer patients: a prospective study. Arch Gynecol Obstet. 2021 Jun;303(6):1581-1588. doi: 10.1007/s00404-020-05896-6. Epub 2021 Jan 6. PMID: 33404703.

18. Endomba FT, Mazou TN, Bigna JJ. Epidemiology of depressive disorders in people living with hypertension in Africa: a systematic review and meta-analysis. BMJ Open. 2020 Dec 10;10(12):e037975. doi: 10.1136/bmjopen-2020-037975. PMID: 33303433; PMCID: PMC7733170.

19. Stanisz M, Panczyk M, Kurzawa R, Grochans E. The Effect of Prophylactic Adnexectomy on the Quality of Life and Psychosocial Functioning of Women with the BRCA1/BRCA2 Mutations. Int J Environ Res Public Health. 2019 Dec 9;16(24):4995. doi: 10.3390/ijerph16244995. PMID: 31818005; PMCID: PMC6950418.

20. Esmaeilzadeh S, Agajani Delavar M, Nouri H, Mashayekh-Amiri S, Ahmadi N, Namdar R. Examination of associations between personality traits, and polymorphisms of MAOA and 5-HTT with the severity of menopausal symptoms and depression levels. Biomed Rep. 2020 May;12(5):259-266. doi: 10.3892/br.2020.1287. Epub 2020 Mar 4. PMID: 32257189; PMCID: PMC7100127. 